\title{
End-of-Life Options for Bio-Based Plastics in a Circular Economy-Status Quo and Potential from a Life Cycle Assessment Perspective
}

\author{
Sebastian Spierling ${ }^{1, *}$, Venkateshwaran Venkatachalam ${ }^{1}$, Marina Mudersbach ${ }^{2}$, Nico Becker ${ }^{3}$, \\ Christoph Herrmann ${ }^{4}\left[{ }^{-}\right.$and Hans-Josef Endres ${ }^{1}$ \\ 1 Institute of Plastics and Circular Economy, Leibniz Universität Hannover, An der Universität 2, 30823 \\ Garbsen, Germany; venkatachalam@ikk.uni-hannover.de (V.V.); endres@ikk.uni-hannover.de (H.-J.E.) \\ 2 Fraunhofer Institute for Wood Research, Application Center for Wood Fiber Research, Heisterbergallee 10A, \\ 30453 Hannover, Germany; marina.mudersbach@wki.fraunhofer.de \\ 3 Institute for Bioplastics and Biocomposites, University of Applied Sciences and Arts Hannover, \\ Heisterbergallee 10A, 30453 Hannover, Germany; nico.becker@hs-hannover.de \\ 4 Institute of Machine Tools and Production Technology, Sustainable Manufacturing \& Life Cycle Engineering, \\ Technische Universität Braunschweig, Langer Kamp 19 B, 38106 Braunschweig, Germany; \\ c.herrmann@tu-braunschweig.de \\ * Correspondence: spierling@ikk.uni-hannover.de; Tel.: +49(0)511-762-13303
}

Received: 30 June 2020; Accepted: 17 July 2020; Published: 21 July 2020

\begin{abstract}
The bio-based plastic market is forecast to grow in the next years. With a growing market share and product range, the implementation of circular thinking is becoming more and more important also for bio-based plastics to enable a sound circular economy for these group of plastics. Therefore, it is important to assess the environmental performance for different end-of-life options of bio-based plastics from an early stage on. This review presents a comprehensive overview on the current status quo of different end-of-life options for bio-based plastics from an environmental perspective. Based on the status quo and the corresponding impact assessment results, the global plastic demand as well as the technical substitution potential of bio-based plastics, the environmental saving potential in case of the different end-of-life options was calculated. The review shows that there is a focus on polylactic acid (PLA) regarding end-of-life assessment, with studies covering all end-of-life options. The focus of the impact assessment has been set on global warming potential (GWP). With respect to GWP, the analysis of a future global potential of PLA showed, for mechanical recycling, the highest saving potential with 94.1 Mio. $\mathrm{t} \mathrm{CO}_{2}$-eq. per year in comparison to virgin material.
\end{abstract}

Keywords: bio-based plastics; life cycle assessment; end-of-life options; circular economy

\section{Introduction}

Plastics are a versatile material group, that has become more and more important in the 20th and 21st century. In the past decades, there has been a rise in the demand and production with a forecast to keep growing within the next decades [1]. But with an ever-increasing population, demand for resources and the challenges to mitigate climate change, an over dependence on the plastics made out of depletable fossil resources have come into focus. Currently, plastics are made of fossil-based resources and mainly used in a linear economy approach (manufacture, use and disposal). In the time period from 1950 till 20154900 Mio. t of plastic has been discarded. However, only a small part of all the produced plastic has actually been recycled, which is around 600 Mio. $t$ of plastic [2]. One of the main use areas of plastic with a long life time are short-life applications in the packaging sector [3], progressively producing big amounts of waste. Therefore, a need for optimized circular economy 
(retaining the value of the plastic within the economy in a loop by not discarding them) pathways for plastics arise.

Bio-based plastics have been identified as a potential alternative to conventional plastics because of the use of renewable resources as feedstock, therefore enabling a shift from a fossil economy to a bio-economy.

Bio-based plastics are classified as two types. They can either be bio-based and biodegradable (e.g., polylactic acid (PLA)) or bio-based and durable (e.g., bio polyethylene (Bio-PE)) [4-6]. Additionally, they can be classified as drop-in or chemical novel types. Chemical novel types offer novel characteristics and have no counterpart in the conventional plastic group (e.g., PLA), whereas the drop-in versions (e.g., Bio-PE) have the same chemical structure and therefore offer the same technical properties and can undergo the same end-of-life treatment options after the use phase as their conventional petro-based counterparts [4,5]. Even if plastics are biobased, the resource efficiency is increased by circular pathways in which end-of-life means a new life option.

The market share of all bio-based plastics is also growing and forecast to grow from 2.15 Mio. $t$ in 2020 to 2.43 Mio. $t$ in 2024 [7] (a growth of 13\%). In alignment with conventional plastics, also bio-based plastics are also mainly used for packaging with more than 53\% market share in 2019 [8]. Accordingly, the aspect of circular economy is as relevant for the bio-based plastics as it is for conventional plastics.

While the drop-in bio-based plastic types have the same end-of-life options as conventional plastics and can fit into the existing recycling processes, the chemical novel types can offer additional options if they are bio-based and biodegradable. That means, that drop-ins are non-degradable as well as their petro-based pendants, whereas the chemical novel bio-based plastics often offer a biodegradability. They offer additional options with regards to aerobic and anaerobic digestion. In Figure 1 an overview of end-of-life options for bio-based plastics is highlighted and connected to the EU waste hierarchy.

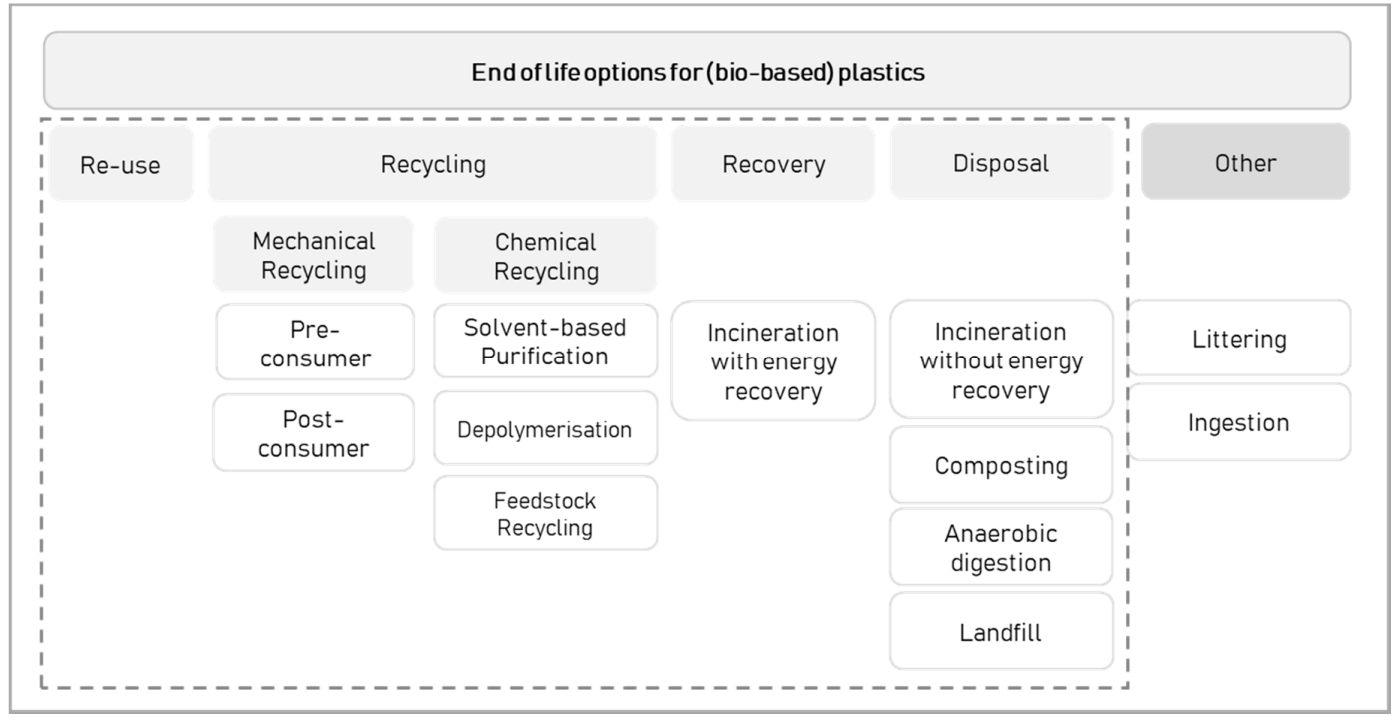

Figure 1. Overview of end-of-life options for bio-based plastics.

According to the EU waste hierarchy [9], prevention and re-use should be at the forefront before considering other end-of-life options. However, re-use is often not feasible e.g., in food packaging applications with a short lifetime [10]. Beside prevention and re-use, several recycling and recovery or disposal options do exist. Furthermore, unintended discarding like littering as well as specific low volume options like ingestion of degradable implants in species (e.g., made of PLA) have to be named as other (un-)intended end of life pathways.

Mechanical recycling comprises mostly physical processing operations. The type of material undergoing mechanical recycling can be classified in pre-consumer or post-industrial material which is mostly scrap or waste material resulting from industrial facilities implying relatively homogenous 
quality and polymer type which can be easily re-extruded. By contrast, the post-consumer material involves far more heterogeneity in material composition and content of impurity which can require washing and sorting processes before starting the physical recycling process. Mechanical recycling involves various pre-treatment processes followed by re-extrusion resulting in a recycling granulate which can be ideally used for products with similar properties like the virgin bio-based plastics. However, because of the mechanical and thermal stress during the recycling process and impurities of the input waste, recyclates from mechanical recycling processes tend to have inferior properties and thus can be used in cascade recycling [11]. The term chemical recycling is not clearly defined, however according to the JRC [12] the term describes reprocessing technologies "using chemical agents or processes that directly affect either the formulation of the plastic or the polymer itself," which leads to the categorization of methods shown in Figure 1. In solvent-based purification a solvent is used to detach the basic polymer from additives and fillers. In chemical depolymerization technology monomers are produced from the plastic waste, which can be used as feedstock for the polymerization of new polymers as the initially polymer type. In feedstock recycling, as e.g., pyrolysis and gasification, thermal processes are used to gather simpler molecules from plastic waste as feedstock for different new polymers with properties of virgin materials [13]. Chemical recycling processes to date only exist at pilot scale level but there are first approaches for industrial facilities on the way [14,15].

For biodegradable bio-based plastics, the degradation property can be used for disposal in industrial composting facilities as well as home composting. During the degradation process $\mathrm{CO}_{2}, \mathrm{H}_{2} \mathrm{O}$ as well as biomass from the microorganisms are produced while breaking down the plastic. Additional humus which sometimes is highlighted as added value of aerobic digestion is not a contribution of biodegradable plastics and can therefore not be claimed [16]. The anaerobic digestion e.g., in biogas plants allows the production of $\mathrm{CH}_{4}$ (along $\mathrm{CO}_{2}$ and $\mathrm{H}_{2} \mathrm{O}$ ) which can be used further for incineration with energy recovery or for the production of bio-based plastics once again (e.g., polyhydroxyalkanoates (PHA) via $\mathrm{CH}_{4}$ ) [17]. Incineration with energy recovery makes use of the relatively high heating value of plastics [4]. The $\mathrm{CO}_{2}$ captured initially by the biomass feedstock used for the production of bio-based plastics is released back into the atmosphere during the incineration process. The produced energy brings an additional benefit to this end-of-life option. Landfill is the storage of waste including plastic without further treatment. However, biodegradable bio-based plastic can degrade under anaerobic conditions (biogas plant) over time and produce $\mathrm{CH}_{4}$, which could either be used as energy source or as feedstock for new plastics. However, if not collected properly, it can also leak into the environment and cause an increased impact on climate change as methane has 25 times higher impact than $\mathrm{CO}_{2}$ [18].

In 2018, 29.1 Mio. $t$ of plastic has been collected in the EU28 + NO/CH area. Approximately 32.5\% of these plastics have been recycled (both in- and outside of Europe), $42.6 \%$ have been incinerated with energy recovery, and 24.9\% deposited in landfill. As of 2018, 10 countries in Europe (EU28 + $\mathrm{NO} / \mathrm{CH}$ ) have landfill restrictions for plastics implemented [19]. While information with regards to the end-of-life fate of plastics are available, this information is not provided separately for bio-based plastics due to their low market share of ca. 1\% [20] and maybe the variety of end-of-life options. As the drop-in types can enter the same end-of-life streams as conventional plastics, the data available for the conventional plastics can be applied for the drop in bio-based plastics as well. Accordingly, end-of-life options of drop-in plastics should not differ from their respective conventional counterpart in the way they are treated, as they are chemically and physically identical.

The novel types require individual end-of-life streams, which still have to be established on an industrial level e.g., for mechanical or chemical recycling. The main share of the novel types is also biodegradable [21] and therefore feeds in the end-of-life option of aerobic and anaerobic digestion, nevertheless also mechanical and chemical recycling can be carried out with these types (e.g., with PLA [22]). For these types, no information on the actual end-of-life fate is available. Nevertheless, it can be assumed (depending on the geographical location), that applications of these types which are associated with biodegradability (e.g., biowaste collection bags) will most likely end up in a degradation facility or degrade in the environment (e.g., mulch films). 
If these materials are used for other applications (e.g., a computer mouse housing), the material will enter the conventional waste streams and will not be separated for further recycling steps due to the low volume in waste streams $[23,24]$. The residues will either be transferred to landfill or to incineration with energy recovery depending on the current end-of-life infrastructure in the respective country.

With regard to the mentioned end-of-life options, it is also important to highlight that the various options on the one hand have different requirements regarding pre-treatment and the infrastructure itself, and on the other hand result in different types of products ranging from $\mathrm{CO}_{2}, \mathrm{H}_{2} \mathrm{O}$, and biomass in the aerobic digestion process to recycled plastic granulate for mechanical recycling and regained feedstock or intermediates for polymerization of new polymers [25]. Therefore, it is important to take into account not only the impact of the end-of-life technology itself, but also the potential benefit of the products resulting from the different options (e.g., secondary plastic or monomers and biogas). To take account of these circumstances in life cycle assessment (LCA), various types of products are credited for the resulting benefit. The products can be linked back in the life cycle of bio-based plastics at different stages (e.g., mechanical recycling into the plastic product production and anaerobic digestion into the production of bio-based plastics via biogas).

The goal of this study is to review the status quo of life cycle assessment of these different end-of-life options of bio-based plastics to highlight the environmental impact associated with the different options and to give an outlook on the future development by calculating the global potential of different circular pathways.

\section{Materials and Methods}

\subsection{Literature Review}

A literature review was carried out based on the existing scientific literature that explicitly used life cycle assessment (LCA) methodology to assess the environmental impacts of different end-of-life options for bio-based plastics. The overall objective of the review is to synthesize the status quo of LCAs assessing end-of-life options for bio-based plastics. To address the objective the following two sub-goals arise: (1) The primary goal is to give an overview of the environmental impact of different end-of-life options for bio-based plastics; (2) a critical aspect affecting the results of LCAs involving bio-based plastics are the methodological choices being made by the LCA practitioners, thus the secondary sub-goal is to qualitatively analyze those methodological choices. Additionally, the results are used to have a look at the global potential of different end-of-life options. LCA is an environmental accounting and management approach that considers all the aspects of resource use and environmental releases associated with an industrial system from cradle-to-grave to assess environmental impacts caused by the system under consideration [26]. The International Organization for Standardization (ISO) has published standards for the preparation of LCAs [27,28]. To the authors best knowledge, no comprehensive analysis focusing on the environmental impacts of end-of-life options of bio-based plastics is available in the scientific literature. Several reviews are available for cradle-to-grave/cradle-to-gate LCA studies [29-31] or for a certain type of polymer/plastic, but not specifically emphasizing different end-of-life options and a broad range of bio-based plastics. To close this gap, this study was performed on the basis of the proposed methodology by Zumsteg et al. for assessing and reporting reviews of LCA data (STARR-LCA) [32] and with general principles for systematic literature reviews [33,34].

The literature was identified via bibliographic database (Web of Knowledge) and the search engines of major publishers (SpringerLink, Elsevier/Sciencedirect, Wiley and Google Scholar). The google search engine was used to include studies that were not published in journals. In an iterative process, the following search words have been combined and used: (1) synonyms for LCA, including "life-cycle-analysis," "life cycle analysis," "life-cycle assessment," and "LCA", (2) the terms "polymer" or "plastic" in combination with the terms "bio-based," "renewable," "green," "renewable materials," "sustainable", (3) different terms for the end-of-life phase, as well as terms for end-of-life options. 
Additionally, studies were searched by cross-checking existing reviews and studies already found. Subsequent to the search, a practical screening was performed by the authors, based on the following criteria: (1) Clear claim to be based on a life-cycle approach to estimate potential environmental impacts and with good and reliable data and references; (2) written in English, process-based LCAs following an attributional modelling approach; (3) assessing at least one production system involving an end-of-life option for bio-based plastics. As a quality benchmark for the reviewed data, only peer reviewed (review process from international scientific journals by colleagues of the scientific community) or critically reviewed (review by life cycle assessment experts in accordance with standards 14040/44 [27,28] publications were considered. This review covers a time period of approximately 10 years, in which a large number of studies have been published. For the review the focus has been set to gain information on the end-of-life phase. Even though studies focusing more on end-of-life were preferred, as it was not feasible, cradle-to-grave LCA studies were analyzed. Within the screening step, 21 suitable studies have been identified which supply primary environmental sustainability information on the end-of-life phase of bio-based plastics. Studies which contain absolute values are shown in Table 1. Studies which have no absolute values but rather relative values are shown in Table S1 in the supplementary information.

Table 1. Overview on life cycle assessment studies for bio-based plastics and end-of-life options with absolute values.

\begin{tabular}{|c|c|c|c|c|c|c|c|c|c|c|c|}
\hline \multirow{2}{*}{$\begin{array}{l}\text { Bio-Based } \\
\text { Plastic }\end{array}$} & \multicolumn{10}{|c|}{ End-of-Life Options } & \multirow{2}{*}{ Source } \\
\hline & MR & CR & SbR & IC & DfS $^{1}$ & IwER & InoER & AD & LFnoER & LFwER & \\
\hline Bio-PET, & & & & & & & & & & & \\
\hline $\begin{array}{c}\text { Bio-HPDE, PLA, } \\
\text { TPS }\end{array}$ & $x$ & & & $x$ & & & & & $x$ & & Hottle et al. 2017 [35] \\
\hline PLA & & & & $x$ & & & & & & $x$ & Suwanmanee et al. 2016 [36] \\
\hline PLA, TPS & $x$ & & & $x$ & $X$ & $x$ & $X$ & $x$ & $x$ & $x$ & Rossi et al. 2015 [37] \\
\hline PLA & $x$ & & & $x$ & & $x$ & & & & $x$ & Gironi and Piemonte 2010 [38] \\
\hline PHA & & & & $x$ & & $x$ & & & & $x$ & Khoo et al. 2010 [39] \\
\hline PLA, PHA, PBS ${ }^{2}$ & $x$ & & & $x$ & & $x$ & & & & & Changwichan et al. 2018 [40] \\
\hline PLA & & & & & & $x$ & & & $X$ & & Choi et al.2018 [41] \\
\hline PLA & & & & $x$ & & $x$ & & & $x$ & $x$ & Papong et al. 2014 [42] \\
\hline PLA & $x$ & $x$ & & $x$ & & & & & & & Cosate de Andrade et al. 2016 [43] \\
\hline PLA & $x$ & $x$ & $x$ & & & $x$ & & & & & Maga et al. 2019 [44] \\
\hline PLA & & & & $x$ & & & & & & & Ingrao et al. 2015 [45] \\
\hline Bio-PE, PLA & & & & $x$ & & $x$ & & $x$ & & $x$ & Hermann et al. 2010 [46] \\
\hline
\end{tabular}

MR: mechanical recycling, CR: chemical recycling, SbR: solvent-based recycling, IC: industrial composting, DfS: direct fuel substitution in plants, IwER: incineration with energy recovery, InoER: incineration without energy recovery, AD: anaerobic digestion, LFnoER: landfill without energy recovery, LFwER: landfilling with energy recovery. ${ }^{1}$ : Describes the energetic utilization of selected waste materials with recoverable calorific value which are used outside a waste incineration plant as substitute for fossil fuels in e.g., cement plants, lime plants, coal fired power plants. ${ }^{2}$ : bio-based.

To be included into the final scope of the review, studies had to further comply with the following requirements: (1) Absolute values of the life cycle impact assessment (LCIA) results are available; and (2) individual end-of-life options were considered separately, no mixed scenarios. All of the LCAs that fulfilled the practical screening and review inclusion criteria were further analyzed in greater detail. The total number of reviewed studies is 12 . This set of studies include the complete literature on LCA of bio-based plastics with an emphasis on the end-of-life phase, which was identified in the literature search in publicly accessible sources and containing sufficient absolute data values. Studies were analyzed following the main phases of the LCA methodology as mentioned by the ISO 14040/44 standards. Table 2 presents the list of the main data and methodological choices retrieved. A quantitative analysis of the LCIA results was performed and wherever feasible we calculated the minimum, maximum, range, and averages of environmental impacts for different types of treatment options and types of plastics. From each study, depending on different aspects like the choice of end-of-life option, the type of bio-based plastics used, methodological aspects (e.g., credit/no credits for the recycling), scenarios were defined accordingly. Consecutively, a qualitative synthesis of the 
retrieved data has been done to discuss influencing methodological choices in the preparation of end-of-life options for bio-based plastics LCAs.

Table 2. Main data and methodological choices retrieved from the life cycle assessment (LCA) studies.

\begin{tabular}{cc}
\hline LCA Phase & Information Extracted from the Studies \\
\hline General information & $\begin{array}{r}\text { Objectives of the study; mention of the focused standard; } \\
\text { assessment tool or software used for modelling }\end{array}$ \\
\hline Goal and scope definition & $\begin{array}{r}\text { Assessed product, type of bio-based polymer/plastic and } \\
\text { end-of-life options; functional unit; system boundaries; } \\
\text { handling of multi-functional processes }\end{array}$ \\
\hline Life-cycle inventory & $\begin{array}{c}\text { Data origin of end-of-life inventories; data representativeness } \\
\text { of end-of-life inventories; handling of treatment credits; types } \\
\text { of waste being treated }\end{array}$ \\
\hline Life-cycle impact assessment & LCIA methods used; impact categories reported; LCIA results \\
\hline
\end{tabular}

\subsection{Method for the Calculation of the Global Potential of Different End-of-Life Options of Bio-Based Plastics}

The aim is to assess the environmental impact resulting from a theoretical global production amount per bio-based plastic being a possible substitute for fossil-based plastics and the related impact from different end-of-life options for those amounts of plastic. This allows to show the most favorable options and possible saving potentials, having end-of-life options resulting for example in secondary materials or energy recovery.

The calculation procedure is shown in Figure 2 and is based on the calculation method applied in Spierling et al. [30]. Herein the global warming potential (GWP) for the production of the global plastic demand of fossil-based plastics was calculated for the annual amount in 2013 and juxtaposed to the GWP that would result, if the amount of plastic globally demanded was completely substituted by bio-based alternatives. This was done to show the lever of potential GWP savings that could possibly be achieved by a maximum rate of substitution. GWP was chosen because of the global relevance and since it provided the only sufficient data basis for the calculation.

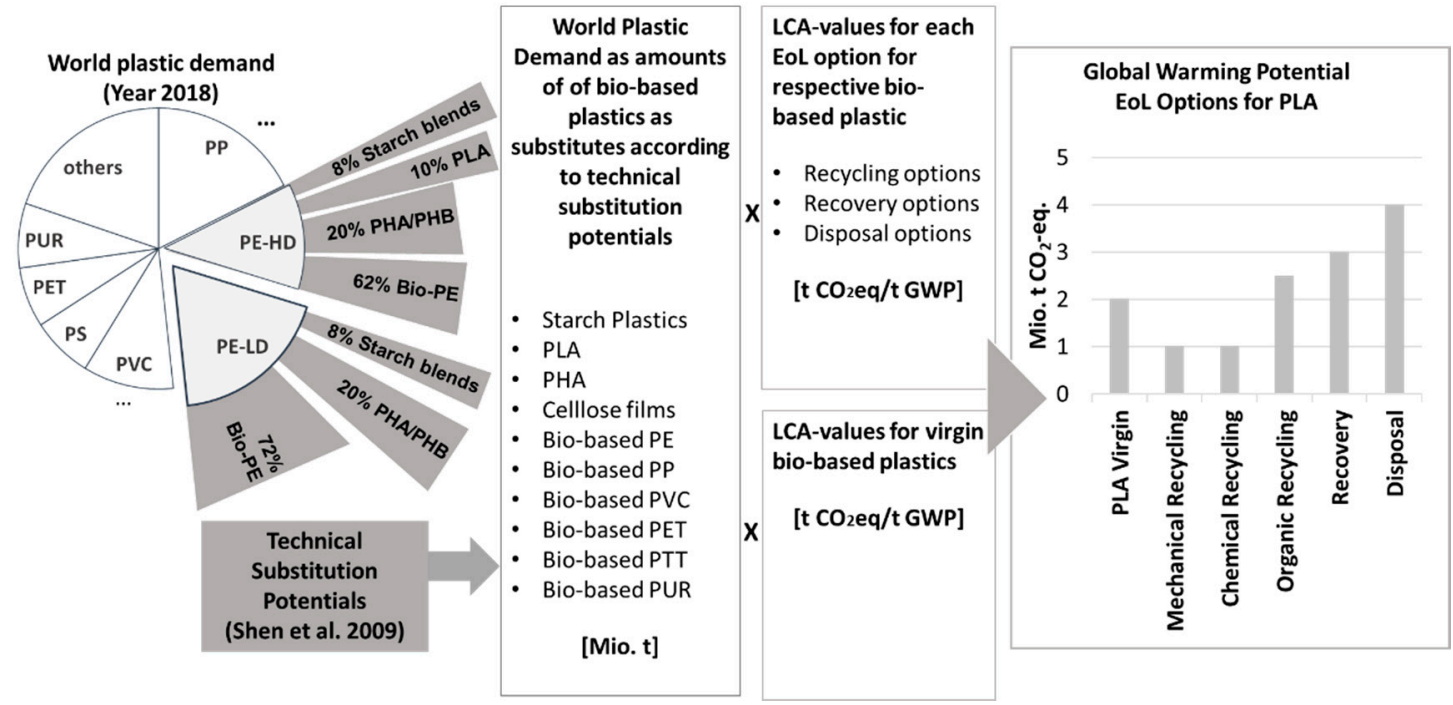

Figure 2. Calculation method for the potential global impact of different end-of-life options of bio-based plastics adapted from Spierling et al. [30].

This calculation is now being followed up on. Based on the world plastic demand (updated to the year 2018 [19] in comparison to Spierling et al. [30] where data from 2013 was used, a detailed overview 
is shown in Table S2 in the supplementary information) and the technical substitution potentials according to Shen et al. [47] the amount of each bio-based plastic type per year corresponding to the global demand is calculated. Environmental impact values for each type of end-of-life option is then applied to the total amount of each bio-based plastic type and put in relation to the impact of the production of virgin material, if feasible. Environmental impact data gained from the literature review are used including minimum, average, and maximum values to show the full spectrum of available data.

\section{Results and Discussion}

\subsection{Literature Review}

Based on the literature review performed, this section describes the analysis of the LCIA results and methodological choices in the preparation of bio-based plastics LCAs which are covering the end-of-life phase. In a quantitative analysis, the LCIA results for a set choice of the most frequently considered impact categories were compiled and compared. Furthermore, the minimum, maximum, and average impacts for each individual end-of-life option corresponding to the bio-based plastics were calculated and will be used as a basis for the calculation of potential global impacts of the different end-of-life options. In a qualitative analysis, influencing methodological choices (e.g., functional unit) were investigated. A total of 87 scenarios were gathered from the 12 studies included in the final scope of the review, with each scenario being considered as separate LCIA result. These scenarios differ in terms of chosen feedstock, maturity of technological level, and the application of accounting credits for subsequently provided functions at the end-of-life option (e.g., recyclate material, energy etc.,). A detailed overview on the different scenarios is shown in Table S3 in the supplementary information.

\subsubsection{Year of Publication}

As shown in Figure 3a, the three oldest studies were published in 2010, the most recent study in 2019, and all other studies between the years 2014 and 2018, so these are basically relatively recent studies. However, the year of publication does not allow to draw conclusions about the actuality of the data being used in the end-of-life inventories and the quality of the study.

\subsubsection{Types of Plastics}

In total, eight different types of bio-based plastics are covered by the studies being reviewed. Figure $3 \mathrm{~b}$ shows the number of individual scenarios per type of plastic. The main focus has been on PLA, which was investigated in 48 scenarios, followed by thermoplastic starch (TPS) with 14 scenarios, PHA with 9 scenarios, and bio-based polybutylene succinate (PBS) with 6 scenarios. The strong focus on PLA is also illustrated by the fact that seven of the studies consider PLA as the only type of plastic in their LCA. The drop-in bio-based plastics were investigated in only a few scenarios, ranging from four for Bio-PE to two scenarios each for high density bio-polyethylene (Bio-HDPE), low density bio-polyethylene (Bio-LDPE), and bio-polyethylene terephthalate (Bio-PET). No data have been identified for the other bio-based plastics like bio-polypropylene, bio-polyamide, bio-polyvinylchloride, bio-polyurethane, regenerated cellulose, cellulose acetate, polyethylene furanoate, polytrimethylene terephthalate. For these types of plastics, either only results are available that do not contain absolute values or there are no available LCAs published yet at all. 


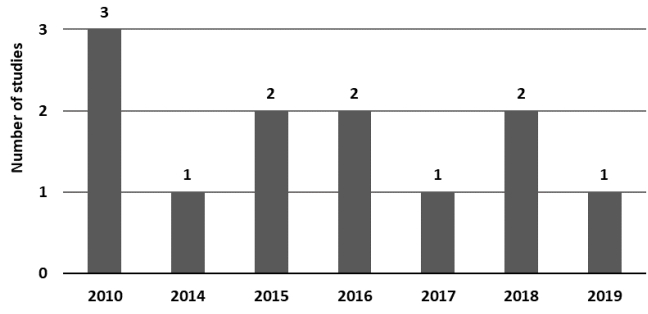

(a) Year of publication

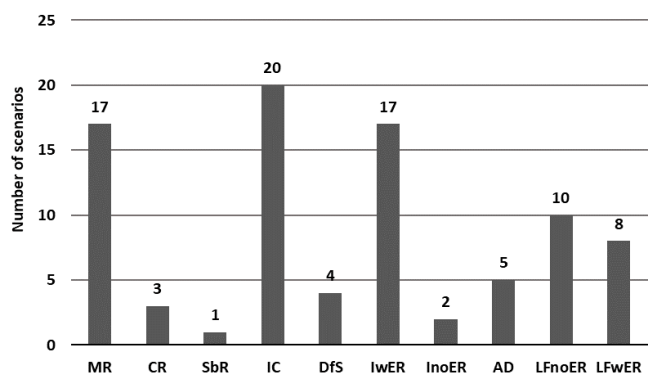

(c) Types of end-of-life options ${ }^{1}$

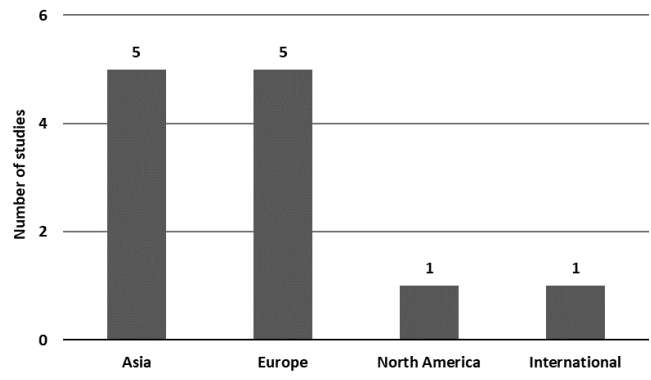

(e) Regional scope

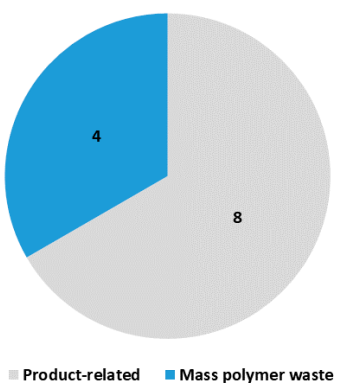

(g) Types of functional units (FU)

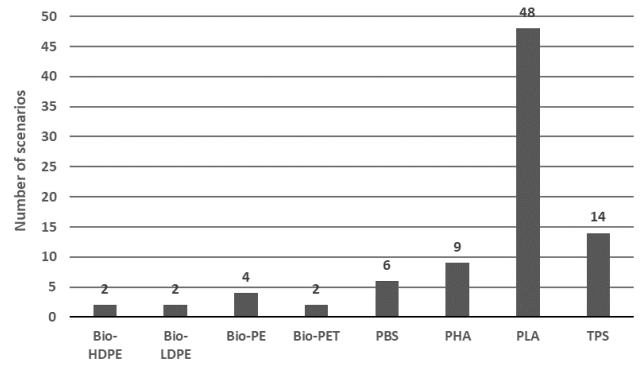

(b) Types of bio-based polymers

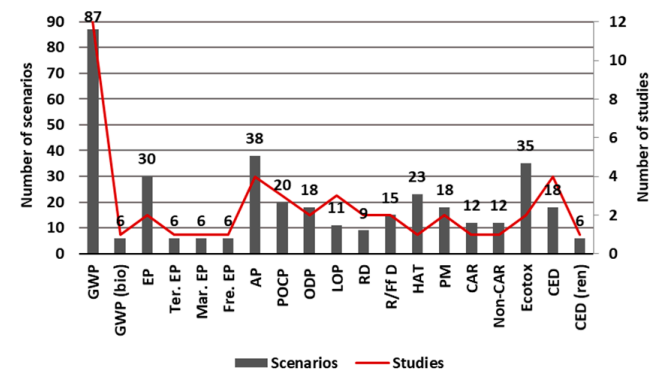

(d) Impact categories included in the reviewed LCAs

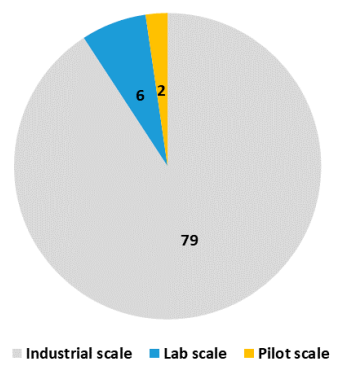

(f) Technological representativeness of end-of-life inventories

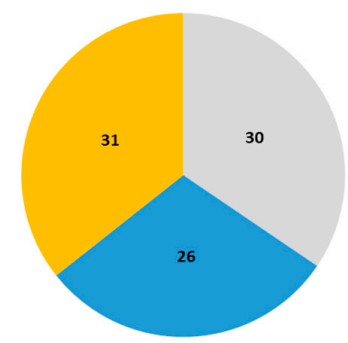

With treatment credits $\approx$ Without treatment credits $\|$ n.a.

(h) Handling of credits for secondary material

Figure 3. Results from the literature review. (a) Year of publication, (b) types of bio-based polymers, (c) types of end-of-life options, (d) impact categories included in the reviewed LCAs, (e) regional scope, (f) technological representativeness of end-of-life inventories, (g) types of functional units (FU), (h) handling of credits for secondary material. ${ }^{1}$ : MR: mechanical recycling, CR: chemical recycling, SbR: solvent-based recycling, IC: industrial composting, DfS: direct fuel substitution in plants, IwER: incineration with energy recovery, InoER: incineration without energy recovery, AD: anaerobic digestion, LFnoER: landfill without energy recovery, LFwER: landfilling with energy recovery. 


\subsubsection{Types of End-of-Life Options}

With the exception of Ingrao et al. [45] all studies consider at least more than one end-of-life option. On average, 3-4 different treatment options are examined by each study. With eight different end-of-life options; Rossi et al. [37] has the largest scope of different options. In total ten end-of-life options have been taken into account: mechanical recycling (MR), chemical recycling (CR), solvent-based recycling (SbR), industrial composting (IC), direct fuel substitution in plants (DfS), incineration with energy recovery (IwER), incineration without energy recovery (InoER), anaerobic digestion (AD), landfill without energy recovery (LFnoER), landfill with energy recovery (LFwER). Figure $3 c$ shows the number of individual scenarios for each end-of-life option. IC was considered most frequently (20/87), followed by incineration (19/87 total, two scenarios of those without energy recovery), landfill (18/87 total, ten scenarios of those without energy recovery), and mechanical recycling (17/87). The other options were only considered in a few scenarios each. Solvent-based recycling (although the authors consider solvent-based recycling as a type of chemical recycling, Maga et al. [38] has considered it as a separate end-of-life option beside the area of chemical recycling. Therefore, solvent-based recycling is shown separately in the results. From all assessed studies just Maga et al. did so.) has only been considered in a single scenario in Maga et al. [44]. The treatment methods household composting, reuse, and litter were not examined in any of the studies; therefore, no data could be obtained.

\subsubsection{LCIA Impact Categories}

The collected inventory data for the product system is quantified as environmental impacts in the LCIA stage of the LCA. There are different LCIA methods that classify and categorize the environmental impacts (climate change, eutrophication, acidification) and the units for these impact indicators as well as the characterization factors that are used to quantify the inventory flows with the impact indicators (GWP, ozone depletion potential (ODP)) can change according to which LCIA method was used for the LCA study.

Figure $3 \mathrm{~d}$ shows the number of studies and scenarios for various impact categories in which they were considered within the scope of the LCIA-phase. The review shows that the most frequently analyzed impact category is GWP, which is the only indicator considered in all studies or scenarios.

The quantitative assessment focused on the impact categories GWP, AP (acidification potential), EP (eutrophication potential), POCP (photochemical ozone creation potential), and ODP, that were addressed frequently and at the same time have scientifically established characterization methods available. The impact categories, abiotic depletion and toxicity potential, play an important role in the analysis of end-of-life options and the handling of wastes and appear predominantly in many publications considered in this review. Especially these indicators show a greater variance in the various LCIA-methodologies regarding the used reference unit to quantify the indicator. This leads to a high inconsistency in the quantified values, which is why they were not further used in our calculation.

In the literature review, it was found that as much as six different LCIA methods like CML, TRACI, ReCiPe, EDIP, IMPACT 2002+, and EcoIndicator have been used. The differences and the consequences in the selection of the impact assessment methods will not be discussed within the scope of this review. For the impact indicator GWP, most of the studies use the characterization factors based on IPCC. It is also evident from the literature review that the GWP is the only indicator with the same unit used consistently across most LCIA methods. Therefore, GWP was considered as the indicator to show the substitution potential in the end-of-life options of bio-based plastics. Also, with regards to GWP, the generic value of GWP was taken without making any distinction whether it includes biogenic carbon (carbon that is absorbed by the biomass during its growth-GWP (bio)) or not. Within the literature review, it was found that only Maga et al. has made the demarcation of GWP including/excluding biogenic carbon dioxide for displaying the LCIA results of different end-of-life options. Therefore, the GWP was considered to be without biogenic carbon. However, these results including biogenic carbon are available in the supplementary Table S4 information. 
In the case of EP, wherever available, the generic EP has been used as an impact indicator with different units. However, in one study (Maga et al. [44]), a classification was done among the different types of EP like terrestrial (ter. EP) and aquatic (freshwater (fre. EP) and marine (mar. EP)). These results were also considered in this review but as separate indicators and were not considered to compute the minimum, maximum, and the average value of the EP for the end-of-life options of the bio-based plastics to avoid double counting. The LCIA results can be found in the supplementary information Table S4. Further impact categories are like carcinogenics (CAR), non-carcinogenics (Non-CAR). Particulate matter (PM), ecotoxicity (Ecotox), land occupation potential (LOP), resource depletion (RD), resource/fossil fuel depletion (R/Ff D), CED (cumulative energy demand), or human toxicity (HAT) have just been considered in a small number of studies or have used difference reference units which prevent comparison.

To analyze the energy consumption for the different end-of-life options, the resource indicator CED was considered. But the energy consumption of the product system was expressed across different studies in the form of primary energy demand (PED), non-renewable energy use, energy demand. However, the cumulative energy demand was selected as a term to be used consistently in this review. If a study distinguishes between renewable and non-renewable energy use or primary and secondary use, the sum of both the values was expressed as the cumulative energy demand for this review.

\subsubsection{Regional Scope/Geographical Representativeness of the Studies}

The majority of LCAs have been prepared in an Asian or European context (5/12 each) regarding the geographical representativeness of the end-of-life inventory (Figure 3e). Within the category "Europe" one study (Maga et al. [44]) explicitly refers to the country Germany, while the other four studies represent a European average. In the category "Asia," one study each refers to Singapore and South Korea, the remaining studies all refer to Thailand. Only one study has been prepared in a North American context (Hottle et al. [35]). Cosate de Andrade et al. [43] are using global averages for the modeling of the end-of-life phase. There is no representative data for the regions Africa, Australia, and South America.

\subsubsection{Technological (Laboratory/Industrial) Representativeness of the Studies/Scenarios}

The majority of the scenarios represent an industrial scale (79/87) with regards to the technological representativeness. Only six scenarios are based on lab scale and two scenarios on pilot scale, see Figure 3f. Of the lab scale scenarios five are for PLA and one is for PHA. With regard to the pilot scale, both are for PLA.

\subsubsection{Type of Waste (Pre-Consumer or Post-Consumer)}

There are generally two types of recycling: pre-consumer and post-consumer. Pre-consumer recycling is the recovery of waste materials generated during the manufacturing or delivery process of goods prior to their delivery to an end user (also termed as post-industrial). Pre-consumer waste recycling is commonly used in manufacturing industries. Post-consumer waste is a material discarded after someone used a product made of it. Post-consumer waste has served its intended purpose and has been discarded for disposal or recovery. Because of the nature of post-consumer recycling, additional transport, collection, sorting, and cleaning are involved in comparison to pre-consumer waste. Scenario 73 and 77 (both Maga et al. [44]) consider pre-consumer waste, all other scenarios post-consumer waste.

\subsubsection{Functional Unit}

The definition of a functional unit (FU) is essential for modelling a product system in LCAs and to allow a comparison of different product systems providing the same function (e.g., conventional plastics compared to bio-based plastics as a food packaging material). The FU is a quantified description of the function of a product that serves as the reference basis (reference flow) for all calculations regarding 
input and output flows and impact assessment results. ISO 14044 states that "the functional unit must be consistent with the aim and scope of the study" [28]. However, the objectives of bio-based plastic LCAs and thus the arguments for a certain functional unit are numerous. Eight of the studies defined a FU which is related to a final plastic product while four studies used a FU based on a certain mass-related amount of polymer or polymeric waste (Figure 3g). Depending on the product type used as FU the technology required for dissembling, transport, sorting etc., might differ and have also an effect on different end-of-life options e.g., with regard to contamination of the plastic.

\subsubsection{System Boundaries}

All studies included in this review follow a cradle-to-grave approach in the choice of system boundaries. There are also studies that explicitly consider only the end-of-life phase, but these only give their results in relative values and are therefore not in the scope of the review.

\subsubsection{Accounting for Credits for Secondary Material}

Credits can be given for the production of energy (e.g., by incineration of plastic waste) or the substitution of virgin material (e.g., substitution of primary plastic by recycled secondary material). In total, 30 scenarios account for credits for secondary material, while 26 are modelled without giving any credits. For 31 scenarios no information regarding the handling of credits is given, (compare Figure 3h). The credits are an important factor in determining the overall environmental impact and benefit of an end-of-life option. As the end-of-life options result in different products and these can be looped back in different stages of the bio-based plastic value chain, the benefits differ. Especially for the end-of-life options resulting in secondary materials which can directly be used for new products (e.g., mechanical recycling) it is important to assess the resulting recycled material appropriately. For example, the substitution rate of virgin plastic by recycling material can differ depending on the application and the quality of the recyclates, causing different substitution ranges which can have a significant impact on the overall performance of the end-of-life option from an environmental perspective.

\subsubsection{Data Quality}

Data are an integral part of LCAs and has a significant influence on the final results. The inventory data used in the studies for this review were a mixture of foreground data collected by the authors, data from LCA databases (commercial and national), literature data, and data based on assumptions. While partly detailed information for single data points in the end-of-life were given e.g., source or time representativeness, no data quality indicators were determined for the studies. This makes an assessment of the data quality of the different studies and the assessed end-of-life options difficult.

\subsubsection{End-of-Life Scenarios}

As this review did not consider the studies with mixed end-of-life options (e.g., 30\% mechanical recycling, 70\% incineration), all the 87 scenarios that have been presented here have the impact assessment results from a single end of life option i.e., 100\% mechanical recycling of products out of PLA, 100\% composting of PHA. Although this assumption is easier for the comparison against different end-of-life options with different bio-based plastics and thereby helpful in calculating the environmental saving potential, this however does not reflect the reality because of the factors associated with the end of life options of plastics like product specific properties, regional environmental regulations, collection of wastes, waste volume, contamination, and sufficient infrastructure.

\subsubsection{Quantitative LCIA Results}

The quantitative LCIA results of the different end-of-life options are shown per $\mathrm{kg}$ of material in Figures 4-8 for the different bio-based plastic types for selected impact categories. In all cases where 
the reference flow does not refer to $1 \mathrm{~kg}$ of material, the results were converted accordingly. Most data have been obtained for the impact category GWP followed by AP, EP, ODP, and POCP. A detailed overview on the different values and further impact categories is shown in Table S3 and S4 in the supplementary information. As a benchmark, the impact of $1 \mathrm{~kg}$ of virgin PLA based on Vink and Davies [48] is highlighted in the figures. With regard to GWP, the end-of-life options MR, CR, and SBR show the best environmental performance on average, however this differs in other impact categories. On average IC, DfS, IwER, InoER, and AD follow in the same ballpark. The highest impact is shown by LFnoER and LFwER. However, with regard to landfill there is a difference in impact between the biodegradable and non-degradable bio-based plastics. The non-degradable once like Bio-PET have a low impact. The degradable once like PLA have a high impact as they degrade in an anaerobic environment and $\mathrm{CH}_{4}$ is created, which can have a high impact on the climate if not collected but emitted into the environment. For the other impact categories (AP, EP, POCP, and ODP) the data availability for the different end-of-life options and bio-based plastics is much lower in comparison to GWP. While the impact for MR shows the lowest impact for GWP, this differs for the impact categories $\mathrm{AP}, \mathrm{EP}, \mathrm{ODP}$, and POCP. For ODP and POCP, the MR shows the highest impact on average. CR and SbR also show the lowest impact for AP, POCP, and ODP, however, this is only for PLA and furthermore no information was available for the impact category EP. Also, LFnoER and LFwER show a lower impact for other impact categories like AP in comparison to the high impact in GWP. The results show that the impact of different end-of-life options differs in the various impact categories analyzed. While MR shows low impact in GWP, its contribution to other impact categories is higher in comparison to other end-of-life options. While CR and SbR show on average the lowest impact in all impact categories, the information for these end-of-life options is just available for PLA and therefore quite limited. To enable a better comparison of the different bio-based plastics as well as end-of-life options more data have to be available. Additionally, methodological aspects influencing the results should be harmonized to gain more comparability for the different data considered. Furthermore, weighting or prioritizing of the impact categories might be a necessary tool in impact assessment to enable an overall comparison, as even with updated data, the different end-of-life options will most likely have advantages and disadvantages in the different impact categories.

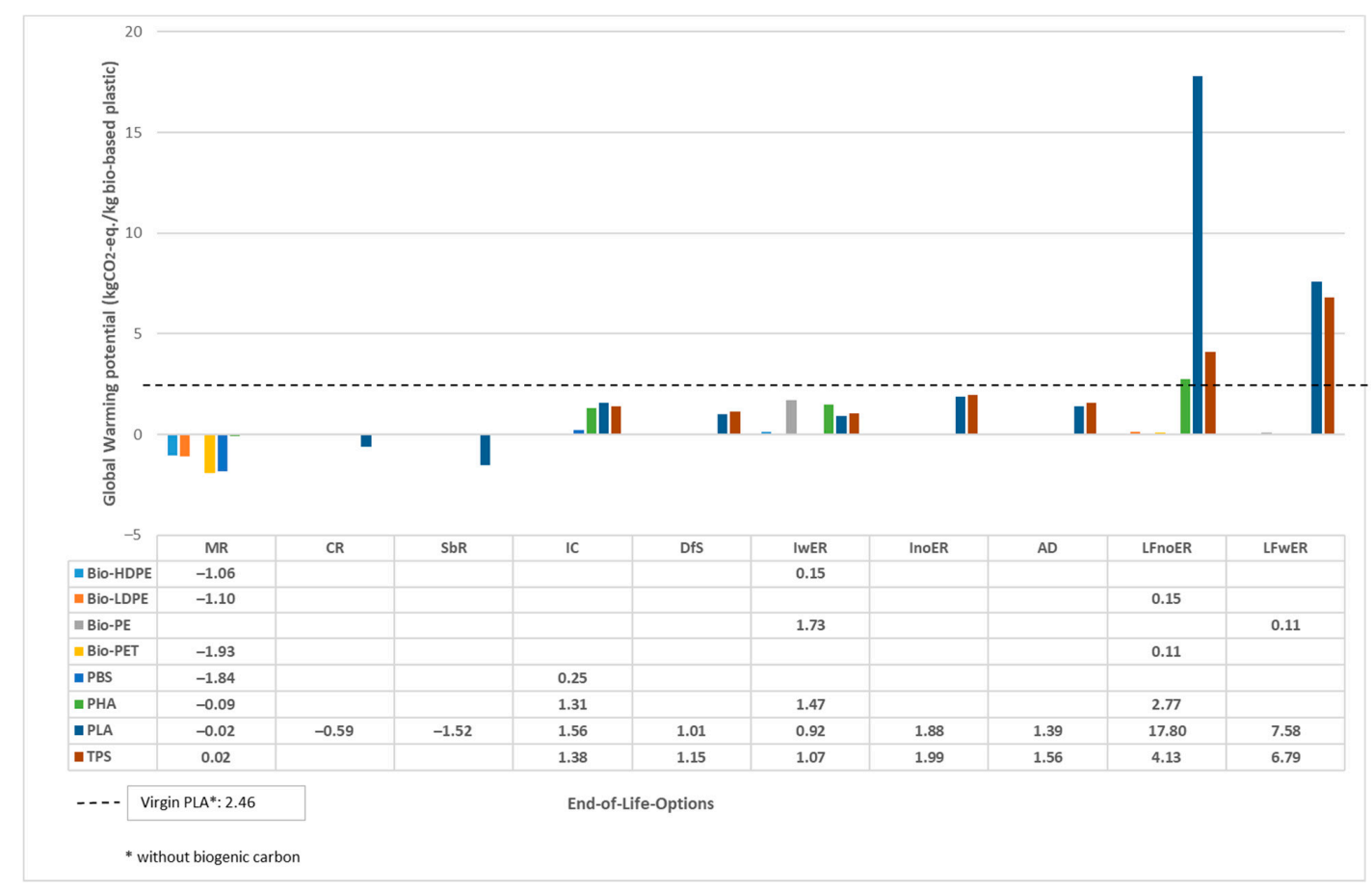

Figure 4. Results from the literature: global warming potential in $\mathrm{kg} \mathrm{CO}_{2}$-eq. per kg bio-based plastic. 


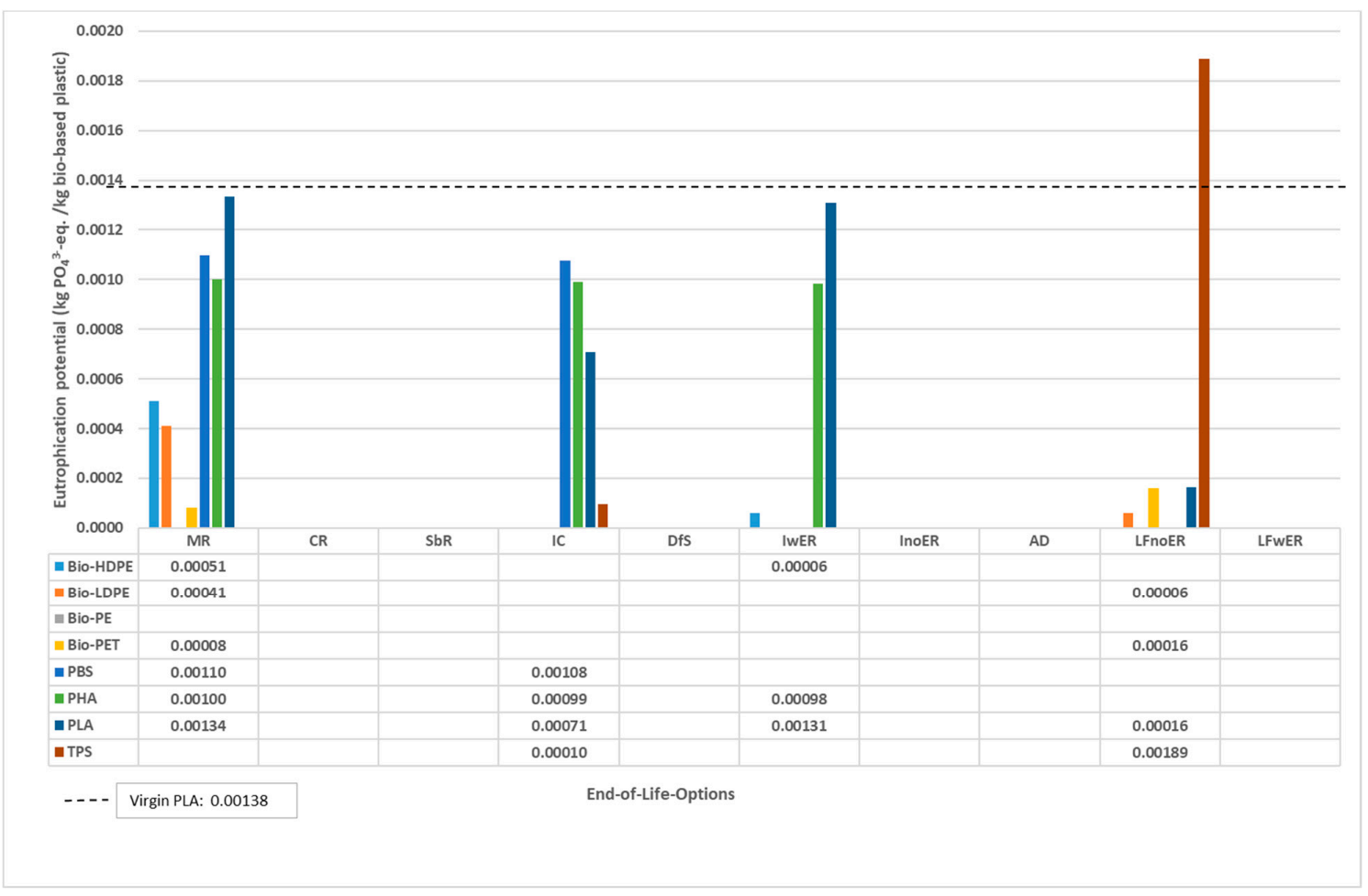

Figure 5. Results from the literature: eutrophication potential in $\mathrm{kg} \mathrm{PO}_{4}{ }^{3-}$-eq. per kg bio-based plastic.

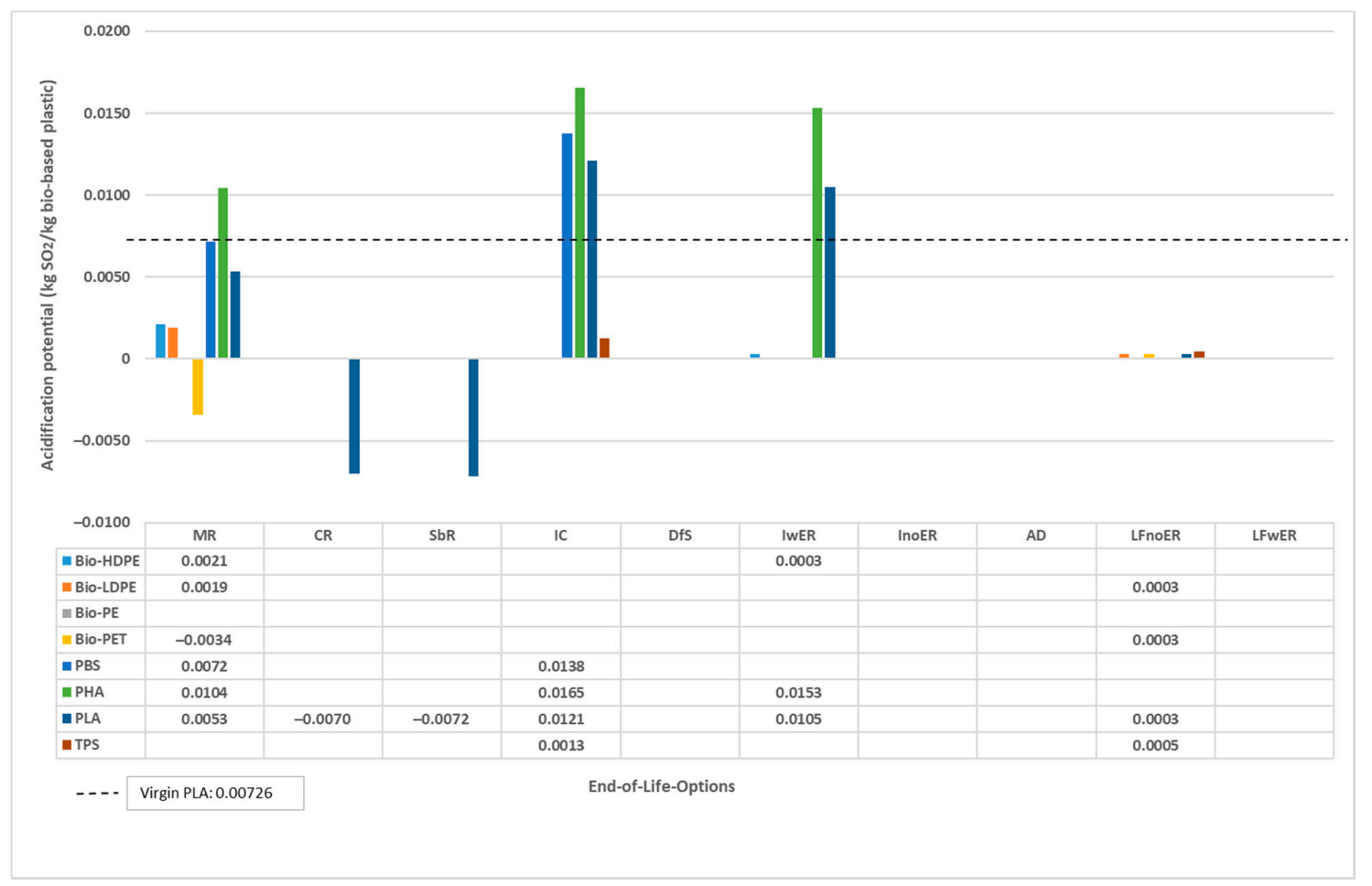

Figure 6. Results from the literature: acidification potential in $\mathrm{kg} \mathrm{SO}_{2}$-eq. per $\mathrm{kg}$ bio-based plastic. 


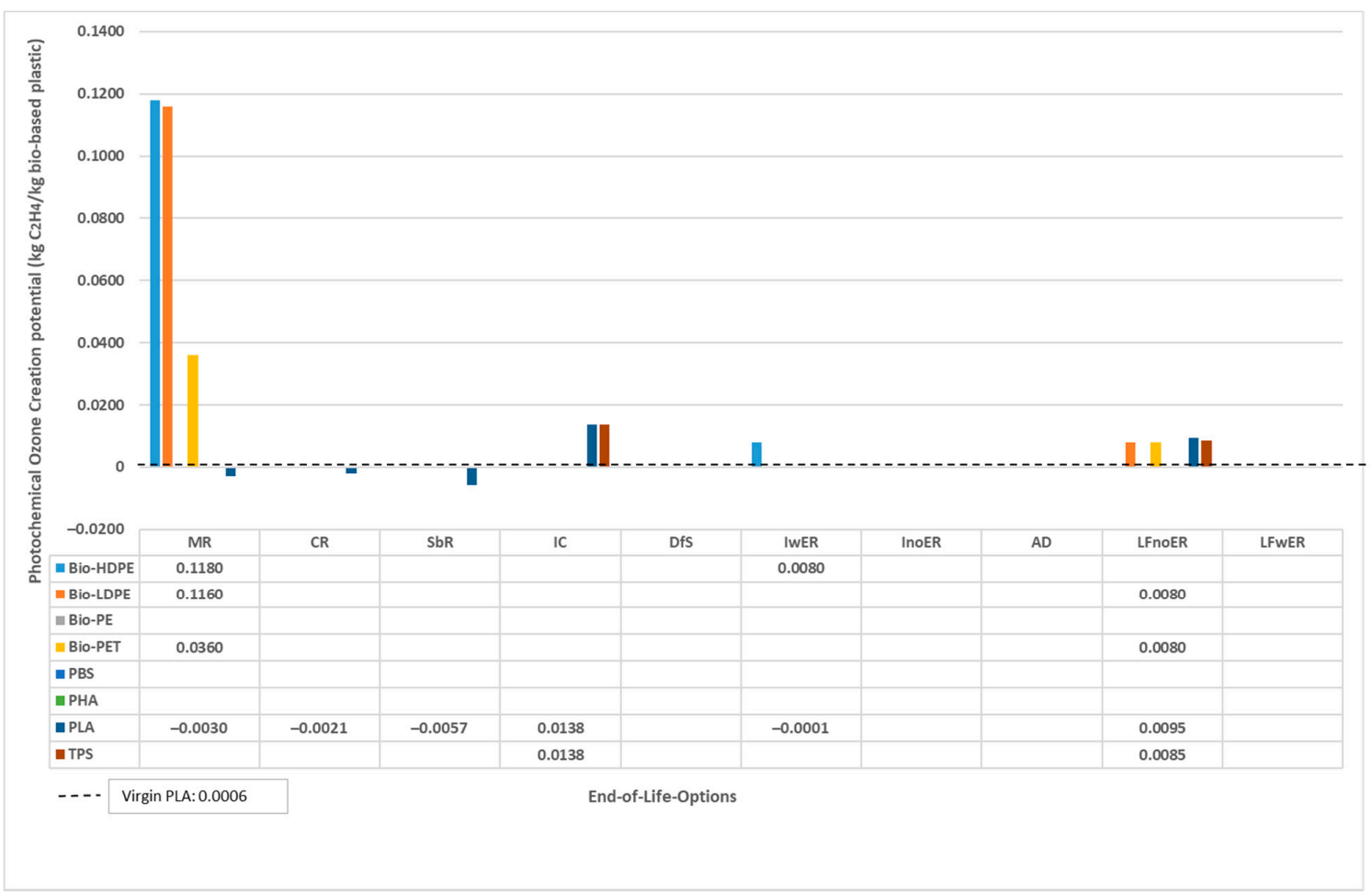

Figure 7. Results from the literature: photochemical ozone creation potential in $\mathrm{kg} \mathrm{C}_{2} \mathrm{H}_{4}$-eq. per $\mathrm{kg}$ bio-based plastic.

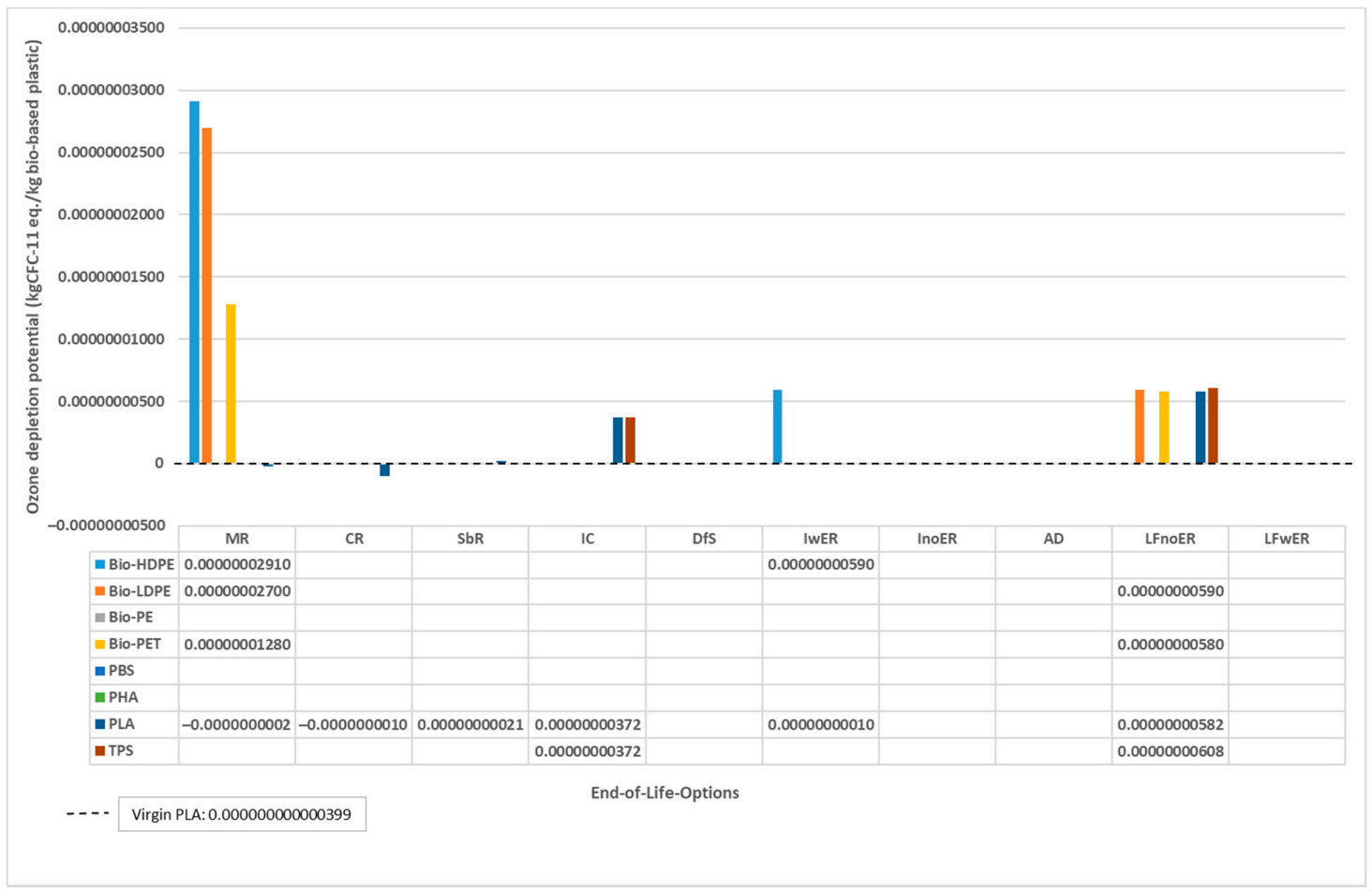

Figure 8. Results from the literature: ozone depletion potential in kgCFC-11-eq. per kg bio-based plastic.

\subsection{Global Potential of Different of End-of-Life Options of Bio-Based Plastics}

The review of available LCA data for bio-based plastics and end-of-life options showed that for most bio-based plastic types and end-of-life options no comprehensive information are available. 
One exemption however was PLA, which provided data for all identified end-of-life options at least for the impact category GWP. Therefore, the method was just applied for PLA and the impact category GWP, the results are shown in Figure 9. The figure shows the global warming potential in $\mathrm{kg} \mathrm{CO}$-eq./global PLA demand. The potential global demand is considered with 19,134,700 t PLA (method from Spierling et al. [30] updated with the latest available data on the plastic demand from 2018 [19]). The GWP is shown for virgin (primary) PLA (based on Vink and Davies [48] without biogenic carbon accounting) as well as following end-of-life options: MR, CR, SbR, IC, DfS, IwER, InoER, AD, LFnoER, LFwER. Minimum, average and maximum values have been considered for each end-of-life option gathered from the different literature sources.

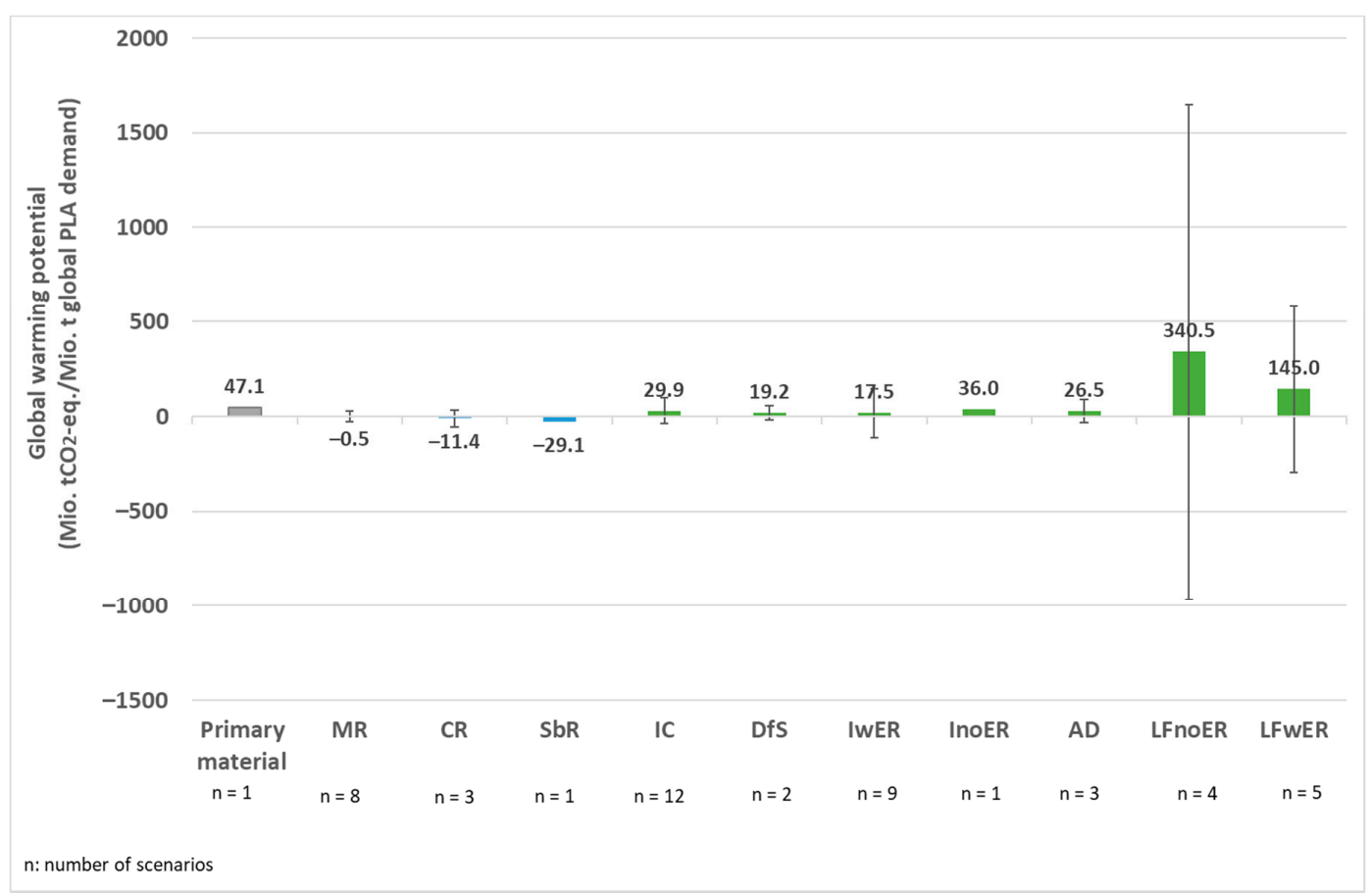

Figure 9. Global warming potential of PLA (primary material, MR, CR, SbR, IC, DfS, IwER, InoER, AD, LFnoER, LFwER for a potential global PLA demand.

The impact for the global demand of PLA is 47.1 Mio. $\mathrm{tCO}_{2}$-eq./ Mio. $\mathrm{t}$ global PLA demand for primary material. Negative values are shown on average for mechanical recycling ( $-0.5 \mathrm{Mio}$. $\mathrm{t} \mathrm{CO}_{2}$-eq.), chemical recycling (-11.4 Mio. $\mathrm{t} \mathrm{CO}_{2}$-eq.), and solvent-based recycling (-29.1 Mio. $\mathrm{t} \mathrm{CO}_{2}$-eq.) therefore offering the highest saving potential. The negative values are caused by the credits that are assigned for the substitution of primary material with the recyclates. The impact categories industrial composting, direct fuel substitution in plants, incineration with energy recovery, incineration without energy recovery, anaerobic digestion show on average an impact between $17.5 \mathrm{Mio} . \mathrm{t} \mathrm{CO}_{2}$-eq. and $36.0 \mathrm{Mio}$. $\mathrm{t} \mathrm{CO}_{2}$-eq per Mio. $\mathrm{t}$ global PLA demand. The highest impact is shown by landfill without energy recovery on average with $340.5 \mathrm{Mio}$. $\mathrm{CO}_{2}$-eq. and landfilling with energy recovery on average with

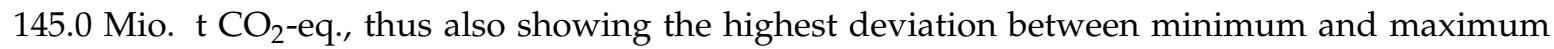
data. For solvent-based recycling and incineration without energy recovery just one source each was identified, which is why the result is without minimum and maximum values.

A method was presented to calculate the environmental potential of end-of-life options of bio-based plastics from a global perspective and therefore enabling a view on the potential contribution of different end-of-life options to a circular economy and showing the saving potential. Because of current limitations in available data for the environmental impacts of bio-based plastics and the corresponding end-of-life options, an assessment was only conducted for the bio-based plastic PLA and the impact category GWP as just for these combination sufficient data were available. The highest saving potential 
was calculated for mechanical recycling, chemical recycling, and solvent-based recycling. The potential ranges between $-0.5 \mathrm{Mio}$. $\mathrm{CO}_{2}$-eq. and $-29.1 \mathrm{Mio}$. $\mathrm{t} \mathrm{CO}_{2}$-eq. In context to the impact of virgin PLA the saving potential for mechanical recycling is 52.1 Mio. $\mathrm{t} \mathrm{CO} 2-e q$. and for solvent based recycling is 76.2 Mio. $\mathrm{t} \mathrm{CO}_{2}$-eq. According to Zheng and Suh [49] the overall life cycle impact of conventional plastics is 1781 Mio. $\mathrm{t} \mathrm{CO}_{2}$-eq. in 2015 (1085 Mio. $\mathrm{t}$ (61\%) for the resin production, $535 \mathrm{Mio}$. $\mathrm{t}$ (30\%) for the conversion, and 161 Mio. $t$. for the end-of-life phase (landfill, recycling, and incineration)) with 407 Mio. $t$ plastics globally been produced in that year. Keeping the saving potential into this context, a reduction of $2.93 \%$ for mechanical recycling and $5.62 \%$ for solvent based recycling could be reached in comparison to overall impact of plastics. In this context it is important to consider that the comparison is based on 407 Mio. $t$ plastics globally produced and the substitution with PLA for 19.13 Mio. t. plastics.

Therefore, method gives a first outlook on the potential of bio-based plastics in a circular economy from an environmental perspective by taking their saving potential into account. However, a couple of current limitations have to be considered. The literature sources used for the environmental data use different data bases, assumptions etc., and therefore causing high deviations between minimum and maximum values in some of the end-of-life options. Therefore, a comparison of results from different sources has to be done with care. A consistent source for environmental data would enable a more reliable comparison. Currently the only available substitution potential for conventional plastics with bio-based plastics has been published by Shen et al. [47]. With emerging research and technologies, an updated version might cause differences in the substitution and therefore in the overall demand for different bio-based plastics types. Additionally, a distribution key for conventional plastic types has been just available for Europe, thus the European key has also been applied for the global data. For the production of secondary materials or energy in an end-of-life option, partly credits have been accounted for. Especially for end-of-life options that create secondary materials which can be directly linked back to the plastics supply chain and therefore substitute virgin material differ in results depending on the substitution rate used (lower technical quality of recycling material in comparison to virgin material-different products need different properties). Furthermore, impacts associated with the degradation like biodiversity or marine litter are not yet taken into account within the current available environmental assessments of the end-of-life options. Assessments of such impact categories might give a better overview to the end-of-life options with degradation properties.

\section{Conclusions}

The literature review showed that an increasing amount of LCA data are available for bio-based plastics and the different available end-of-life options. However, the main focus of the studies is set on PLA and GWP, thus making it the only bio-based plastic which provides information for all end-of-life options. For a comprehensive assessment of bio-based plastics, the available information on end-of-life options as well as impact assessment categories are not sufficient. A procedure has been highlighted to give a basis for the discussion on the potential impact of bio-based plastics in a circular economy. While the data availability for a comprehensive assessment is still too small, a first assessment has been conducted for PLA and GWP for all end-of-life options taken into account. With improved data, the procedure could provide comprehensive assessments for all available end-of-life options of bio-based plastics and thus showing the potential but also limitations of bio-based plastics in a circular economy. This procedure, along with sufficient information could pave way to develop research activities and circular economy pathways for bio-based plastics in the future.

Supplementary Materials: The following are available online at http:/www.mdpi.com/2079-9276/9/7/90/s1. Table S1: Overview identified publications without absolute values, Table S2: Bio-based plastic demand used for the calculation, Table S3: Results of the literature review (87 scenarios), Table S4: Average, minimum, and maximum values of the literature review per bio-based plastic type and end-of-life option. 
Author Contributions: Conceptualization, S.S., V.V., M.M., N.B., C.H., and H.-J.E.; methodology, S.S., V.V., M.M., N.B., C.H., and H.-J.E.; validation, M.M., C.H., and H.-J.E.; formal analysis, S.S., V.V., M.M., and N.B.; investigation, S.S., V.V., M.M., and N.B.; resources, S.S., V.V., M.M., and N.B.; data curation, S.S., V.V., M.M., and N.B.; writing - original draft preparation, S.S., V.V., M.M., and N.B.; writing-review and editing, S.S., V.V., M.M., N.B., C.H., and H.-J.E.; visualization, S.S., M.M., and N.B.; supervision, C.H. and H.-J.E. All authors have read and agreed to the published version of the manuscript.

Funding: This research received no external funding.

Acknowledgments: The authors would like to thank the editor of this special issue for his ongoing support and the review team for their critical feedback and support.

Conflicts of Interest: The authors declare no conflict of interest.

\section{References}

1. Global Plastics Market Analysis. Available online: https://www.grandviewresearch.com/press-release/globalplastics-market-analysis (accessed on 26 June 2020).

2. Geyer, R.; Jambeck, J.R.; Law, K.L. Production, use, and fate of all plastics ever made. Sci. Adv. 2017, 3, e170782. [CrossRef] [PubMed]

3. Plastics the Facts 2018. Available online: https://www.plasticseurope.org/application/files/6315/4510/9658/ Plastics_the_facts_2018_AF_web.pdf (accessed on 26 June 2020).

4. Endres, H.-J.; Siebert-Raths, A. Engineering Biopolymers; Hanser: Munich, Germany, 2011. [CrossRef]

5. Biopolymers Facts and Statistics. 2019. Available online: https://www.ifbb-hannover.de/files/IfBB/downloads/ faltblaetter_broschueren/f+s/Biopolymers-Facts-Statistics-2019.pdf (accessed on 26 June 2020).

6. Blanco, I.; Ingrao, C.; Siracusa, V. Life-cycle assessment in the polymeric sector: A comprehensive review of application experiences on the Italian scale. Polymers 2020, 12, 1212. [CrossRef] [PubMed]

7. Bioplastic Market Data-Global Production Capacity 2018-2024. Available online: https://www.europeanbioplastics.org/wp-content/uploads/2019/11/Global_Production_Capacity_2018-2024_en.jpg (accessed on 26 June 2020).

8. Bioplastic Market Data-Global Production Capacity 2019 by Market Segment. Available online: https://www.european-bioplastics.org/wp-content/uploads/2019/11/Global_Production_Capacity_2019_ by_market_segment_en.jpg (accessed on 26 June 2020).

9. EU Directive on Waste and Repealing Certain Directives 2008. Available online: https://eur-lex.europa.eu/ legal-content/EN/TXT/?uri=CELEX:32008L0098 (accessed on 26 June 2020).

10. Spierling, S.; Röttger, C.; Venkatachalam, V.; Mudersbach, M.; Herrmann, C.; Endres, H.-J. Bio-based plastics-A building block for the circular economy? Procedia CIRP 2018, 69, 573-578. [CrossRef]

11. Hildebrandt, J.; Bezama, A.; Thrän, D. Cascade use indicators for selected biopolymers: Are we aiming for the right solutions in the design for recycling of bio-based polymers? Waste Manag. Res. 2017, 35, 367-378. [CrossRef]

12. A Circular Economy for Plastics. Available online: https:/op.europa.eu/en/publication-detail/-/publication/ 33251cf9-3b0b-11e9-8d04-01aa75ed71a1/language-en/format-PDF/source-87705298 (accessed on 26 June 2020).

13. El Dorado of Chemical Recycling. Available online: https://circulareconomy.europa.eu/platform/sites/default/ files/2019_08_29_zwe_study_chemical_recycling.pdf (accessed on 26 June 2020).

14. La Rosa, A.D.; Blanco, I.; Banatao, D.R.; Pastine, S.J.; Björklund, A.; Cicala, G. Innovative chemical process for recycling thermosets cured with Recyclamines ${ }^{\circledR}$ by converting bio-epoxy composites in reusable thermoplastic-An LCA study. Materials 2018, 11, 353. [CrossRef]

15. Thiounn, T.; Smith, R.C. Advances and approaches for chemical recycling of plastic waste. J. Polym. Sci. 2020, 58, 1347-1364. [CrossRef]

16. OWS Expert Statement (Bio)Degradable Mulching Films. Available online: https://docs.european-bioplastics. org/publications/OWS_Expert_statement_mulching_films.pdf (accessed on 26 June 2020).

17. Luangthongkam, P.; Strong, P.J.; Mahamud, S.N.S.; Evans, P.; Jensen, P.; Tyson, G.; Laycock, B.; Lant, P.A.; Pratt, $\mathrm{S}$. The effect of methane and odd-chain fatty acids on 3-hydroxybutyrate $(3 \mathrm{HB})$ and 3-hydroxyvalerate (3HV) synthesis by a Methylosinus-dominated mixed culture. Bioresour. Bioprocess. 2019, 6, 1-10. [CrossRef]

18. 2019 Refinement to the 2006 IPCC Guidelines for National Greenhouse Gas Inventories. Available online: https://www.ipcc-nggip.iges.or.jp/public/2019rf/vol1.html (accessed on 26 June 2020). 
19. Plastics the Facts 2019. Available online: https://www.plasticseurope.org/application/files/9715/7129/9584/ FINAL_web_version_Plastics_the_facts2019_14102019.pdf (accessed on 26 June 2020).

20. Bioplastic Market Data. Available online: https://www.european-bioplastics.org/market/ (accessed on 26 June 2020).

21. Bioplastic Market Data-Global Production Capacity 2019 by Material Type Percentage. Available online: https://www.european-bioplastics.org/wp-content/uploads/2019/11/Global_Production_Capacity_ 2019_by_material_type_percentage_en.jpg (accessed on 26 June 2020).

22. Piemonte, V.; Sabatini, S.; Gironi, F. Chemical Recycling of PLA: A Great Opportunity Towards the Sustainable Development? J. Polym. Environ. 2013, 21, 640-647. [CrossRef]

23. Gere, D.; Czigany, T. Rheological and mechanical properties of recycled polyethylene films contaminated by biopolymer. Waste Manag. 2018, 76, 190-198. [CrossRef]

24. Wojnowska-Baryła, I.; Kulikowska, D.; Bernat, K. Effect of bio-based products on waste management. Sustainability 2020, 12, 2088. [CrossRef]

25. Soroudi, A.; Jakubowicz, I. Recycling of bioplastics, their blends and biocomposites: A review. Eur. Polym. J. 2013, 49, 2839-2858. [CrossRef]

26. Curran, M.A. Life-Cycle assessment. In Encyclopedia of Ecology; Jørgensen, S.E., Fath, B.D., Eds.; Elsevier: Amsterdam, the Netherlands, 2008; pp. 2168-2174. ISBN 9780080454054. [CrossRef]

27. International Organization for Standardization. ISO 14040:2006. Environmental Management-Life Cycle Assessment-Principles and Framework; International Organization for Standardization: Geneva, Switzerland, 2006.

28. International Organization for Standardization. ISO 14044:2006. Environmental Management-Life Cycle Assessment-Requirements and Guidelines; International Organization for Standardization: Geneva, Switzerland, 2006.

29. Hottle, T.; Bilec, M.; Landis, A. Sustainability assessments of bio-based polymers. Polym. Degrad. Stab. 2013, 98, 1898-1907. [CrossRef]

30. Spierling, S.; Knüpffer, E.; Behnsen, H.; Mudersbach, M.; Krieg, H.; Springer, S.; Albrecht, S.; Herrmann, C.; Endres, H.-J. Bio-based plastics-A review of environmental, social and economic impact assessments. J. Clean. Prod. 2018, 185, 476-491. [CrossRef]

31. Yates, M.R.; Barlow, C.Y. Life cycle assessments of biodegradable, commercial biopolymers-a critical review. Resour. Conserv. Recycl. 2013, 78, 54-66. [CrossRef]

32. Zumsteg, J.M.; Cooper, J.S.; Noon, M.S. Systematic review checklist-a standardized technique for assessing and reporting reviews of life cycle assessment data. J. Ind. Ecol. 2012, 16, 12-21. [CrossRef]

33. Fink, A. Conducting Research Literature Reviews: From the Internet to Paper; Sage Publications: Thousand Oaks, CA, USA, 2010.

34. Borrego, M.; Foster, M.J.; Froyd, J.E. Systematic literature reviews in engineering education and other developing interdisciplinary fields. J. Eng. Educ. 2014, 103, 45-76. [CrossRef]

35. Hottle, T.; Bilec, M.; Landis, A. Biopolymer production and end of life comparisons using life cycle assessment. Resour. Conserv. Recycl. 2017, 122, 295-306. [CrossRef]

36. Suwanmanee, U.; Leejarkpai, T.; Mungcharoen, T. Comparative assessment of global warming impact and eco-efficiency of PS (polystyrene), PET (polyethylene terephthalate) and PLA (polylactic acid) boxes. J. Clean. Prod. 2016, 125, 95-107. [CrossRef]

37. Rossi, V.; Cleeve-Edwards, N.; Lundquist, L.; Schenker, U.; Dubois, C.; Humbert, S.; Jolliet, O. Life cycle assessment of end-of-life options for two biodegradable packaging materials: Sound application of the European waste hierarchy. J. Clean. Prod. 2015, 86, 132-145. [CrossRef]

38. Gironi, F.; Piemonte, V. Life cycle assessment of polylactic acid and polyethylene terephthalate bottles for drinking water. Environ. Prog. Sustain. Energy 2011, 30, 459-468. [CrossRef]

39. Khoo, H.H.; Tan, R.B.H. Environmental impacts of conventional plastic and bio-based carrier bags. Int. J. Life Cycle Assess. 2010, 15, 338-345. [CrossRef]

40. Changwichan, K.; Silalertruksa, T.; Gheewala, S.H. Eco-Efficiency Assessment of bioplastics production systems and end-of-life options. Sustainability 2018, 10, 952. [CrossRef]

41. Choi, B.; Yoo, S.; Park, S.-I. Carbon footprint of packaging films made from LDPE, PLA, and PLA/PBAT blends in South Korea. Sustainability 2018, 10, 2369. [CrossRef] 
42. Papong, S.; Malakul, P.; Trungkavashirakun, R.; Wenunun, P.; Chom-in, T.; Nithitanakul, M.; Sarobol, E. Comparative assessment of the environmental profile of PLA and PET drinking water bottles from a life cycle perspective. J. Clean. Prod. 2014, 65, 539-550. [CrossRef]

43. De Andrade, M.F.C.; Souza, P.M.S.; Cavalett, O. Life cycle assessment of Poly(Lactic Acid) (PLA): Comparison between chemical recycling, mechanical recycling and composting. J. Polym. Environ. 2016, 24, 372-384. [CrossRef]

44. Maga, D.; Hiebel, M.; Thonemann, N. Life cycle assessment of recycling options for polylactic acid. Resour. Conserv. Recycl. 2019, 149, 86-96. [CrossRef]

45. Ingrao, C.; Tricase, C.; Cholewa-Wójcik, A.; Kawecka, A.; Rana, R.; Siracusa, V. Polylactic acid trays for fresh-food packaging: A Carbon Footprint assessment. Sci. Total Environ. 2015, 537, 385-398. [CrossRef]

46. Hermann, B.G.; Blok, K.; Patel, M.K. Twisting biomaterials around your little finger: Environmental impacts of bio-based wrappings. Int. J. Life Cycle Assess. 2010, 15, 346-358. [CrossRef]

47. Product Overview and Market Projection of Emerging Bio-Based Plastics, PRO-BIP 2009. Available online: http://news.bio-based.eu/media/news-images/20091108-02/Product_overview_and_market_projection_ of_emerging_bio-based_plastics,_PRO-BIP_2009.pdf (accessed on 26 June 2020).

48. Vink, E.; Davies, S. Life Cycle Inventory and impact assessment data for 2014 IngeoTM polylactide production. Ind. Biotechnol. 2015, 11, 167-180. [CrossRef]

49. Zheng, J.; Suh, S. Strategies to reduce the global carbon footprint of plastics. Nat. Clim. Chang. 2019, 9, 374-378. [CrossRef]

(C) 2020 by the authors. Licensee MDPI, Basel, Switzerland. This article is an open access article distributed under the terms and conditions of the Creative Commons Attribution (CC BY) license (http://creativecommons.org/licenses/by/4.0/). 